\title{
Article \\ Design and Implementation of the Bidirectional DC-DC Converter with Rapid Energy Conversion
}

\author{
Bing-Zhang Chen ${ }^{1}$, Hsuan Liao ${ }^{1, *} \mathbb{C}$, Linda Chen ${ }^{2} \mathbb{C}$ and Jiann-Fuh Chen ${ }^{1}$ \\ 1 Department of Electrical and Electronics Engineering, National Cheng Kung University, Tainan 701, Taiwan; \\ brian23330113@gmail.com (B.-Z.C.); chenj@@mail.ncku.edu.tw (J.-F.C.) \\ 2 Department of Electrical and Computer Engineering, University of Canterbury, \\ Christchurch 8041, New Zealand; linday.chen@canterbury.ac.nz \\ * Correspondence: n28064046@gs.ncku.edu.tw
}

check for updates

Citation: Chen, B.-Z.; Liao, H.; Chen, L.; Chen, J.-F. Design and Implementation of the Bidirectional DC-DC Converter with Rapid Energy Conversion. Energies 2022, 15, 898. https://doi.org/10.3390/en15030898 Academic Editors: Alon Kuperman, Ching-Ming Lai and Yitao Liu

Received: 27 December 2021

Accepted: 21 January 2022

Published: 26 January 2022

Publisher's Note: MDPI stays neutral with regard to jurisdictional claims in published maps and institutional affiliations.

Copyright: (c) 2022 by the authors. Licensee MDPI, Basel, Switzerland. This article is an open access article distributed under the terms and conditions of the Creative Commons Attribution (CC BY) license (https:// creativecommons.org/licenses/by/ $4.0 /)$.

\begin{abstract}
The bidirectional DC-DC converters are widely used in the energy storage system (ESS) and DC distribution system. The power capacity is limited when the converter is operated with smooth power transfer. In addition, the directions of the inductor current and the capacitor voltage cannot change instantaneously. In this study, a rapid energy conversion technique for smoothing and accelerating the energy transfer under the same specification of the main components in steady state is proposed. Moreover, a bidirectional DC-DC converter with a high conversion ratio is proposed to overcome the commonly low voltage input from renewable energy sources. The operating principles of the proposed converter's step-down and step-up modes are discussed in this study. Furthermore, to achieve rapid energy conversion, digital control is a crucial component in the converter system. A digital signal processor is used as the control platform, and a control strategy is formulated to achieve rapid energy conversion. The bidirectional DC-DC prototype converter with a $24 \mathrm{~V}$ battery, a DC bus of $200 \mathrm{~V}$, and an output power of $500 \mathrm{~W}$ is constructed to confirm the feasibility of rapid energy conversion. The proposed converter can be operated in CCM, BCM, and DCM conditions. The transfer period can be completed within one switching cycle when the proposed converter is operated in BCM or DCM. The energy is freewheeled before energy conversion when the proposed converter is operated in CCM condition. In the experiment, the minimum transfer period is $6.29 \mu \mathrm{s}$ on the DCM stage.
\end{abstract}

Keywords: bidirectional DC-DC converter; rapid energy conversion; smooth power transfer

\section{Introduction}

In recent years, because of fast economic development, energy demands have increased rapidly, which, in consequence, caused damages to the environment and accelerated global warming during power generation. To achieve sustainable development of society and economy, environmental protection and the usage of energy have become the most important aspects [1-6]. In addition, renewable energy sources such as wind energy and solar energy are regeneratable and cause less environmental pollution when compared with conventional fossil fuel power generation. However, due to the instability in the renewable energy sources, the methods for smoothing the input energy are essential. Therefore, it is getting more common for the renewable energy system (RES) to integrate with the energy storage system (ESS) [7-10]. Figure 1 shows the RES incorporating batteries as the backup power [11]. Bryden et al. illustrated the advantages of the usage of stationary energy storage [11]. The electric vehicle (EV) charging stations can buffer the energy between the electricity grid and EVs, minimizing the maximum power required for grid connection. There are, however, some issues with the connection between the grid and converters, such as the stability of the power flow and the time required for energy transfer. The quality of the power flow and the length of the conversion time for energy transfer are the main aspects being studied in this research. 
In modern days, uninterruptible power supply (UPS) systems are usually used at the utility grid as the main power source and the batteries are used as a backup power source $[12,13]$. Thus, for systems interfacing the ESS with the DC bus, the bidirectional DC-DC converters with power flow control have been widely discussed for effective power conversion [14-21]. Several research groups have discussed the possible methods of improving the quality of the power flow by modifying the circuit topology [14-17]. Vuyyuru et al. and Khan et al. have also illustrated different control strategies for improving the power flow quality [18-20]. In this study, we combined a control strategy designed for the proposed topologies of the DC-DC converter with a short conversion period.

The terminal voltages of renewable energy sources are usually low and with timedependent variations. Hence, a bidirectional DC-DC converter with a high conversion ratio is commonly used to interface with the DC bus to provide stable power energy. The converter needs to reduce the load current for a smooth power transfer [21-26], which, in consequence, limits the power capacity during conversion $[19,26]$. Thus, this paper also analyzes the energy conversion between operating modes and proposes a technique for rapid energy conversion.

A bidirectional DC-DC converter with a short conversion period is proposed in this paper. Two different condition modes are discussed. One is the discontinuous conduction mode $(\mathrm{DCM})$, or boundary conduction mode $(\mathrm{BCM})$, and the other is the continuous conduction mode (CCM). In general, the inductor current decreases to zero within one switching period which allows the completion of the energy conversion in one switching cycle. However, the change of the value of the inductor current is not instantaneous. To prevent damages to components in the converter due to the high voltage spike, the inductor current should be freewheeling in the CCM condition. Therefore, the freewheeling path period needs to be considered as well.

In this paper, Section 2 discusses the operational principle of the proposed DC-DC converter with a high conversion ratio. The operational principles of the step-up mode and step-down mode are discussed. Section 3 describes the proposed control strategy of the transferring state for rapid energy conversion. A bidirectional DC-DC converter circuit is constructed with a battery voltage of $24 \mathrm{~V}$ and a $200 \mathrm{~V}$ DC bus voltage for the validation of the proposed topology design. The experimental results are presented in Section 4, followed by the conclusions and future works in the final section.

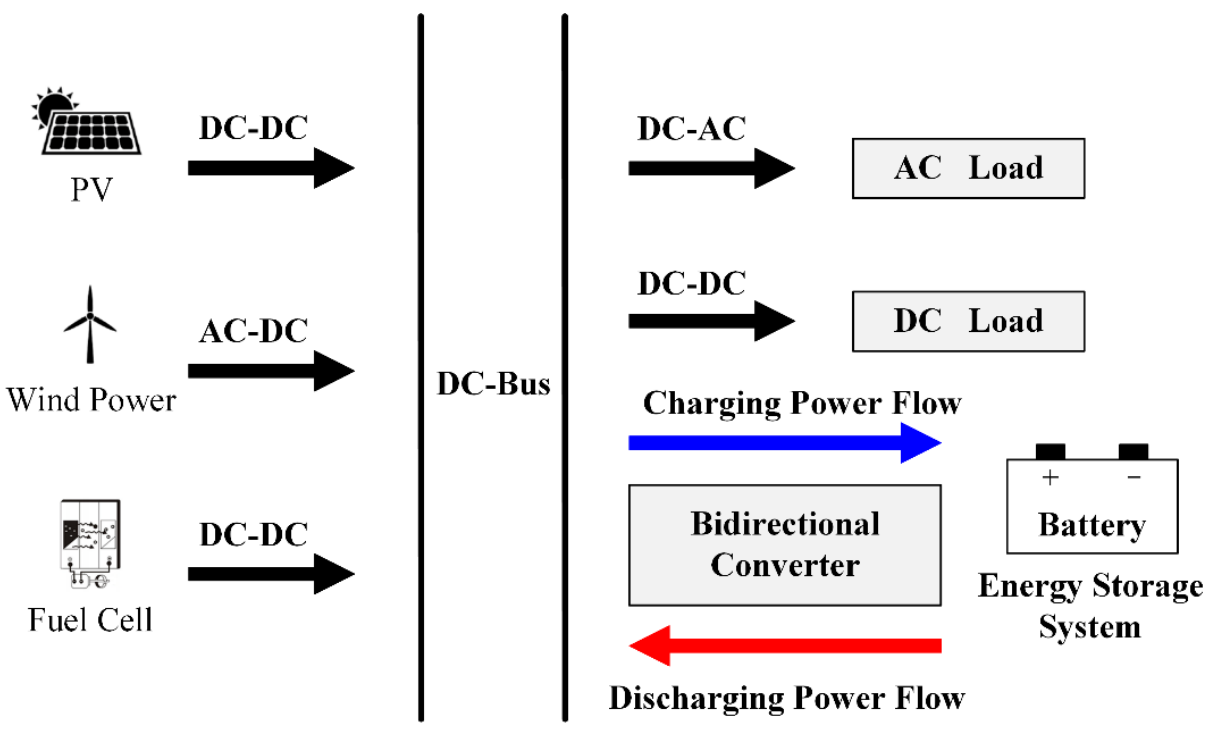

Figure 1. A backup battery in interfacing with various power supplies. 


\section{Operational Principle of Proposed Converter}

The operational principles of the proposed bidirectional DC-DC converter are analyzed and presented in this section. Figure 2 shows the topology of the proposed bidirectional DC-DC converter, which is composed of a battery voltage $V_{b a t}$, a DC bus voltage $V_{d c, b u s}$, five power switches $S_{1}, S_{2}, S_{3}, S_{A u x 1}$, and $S_{A u x 2}$, two inductors $L_{1}$ and $L_{2}$, and two capacitors $C_{b a t}$ and $C_{b u s}$. Two auxiliary switches are used as the bidirectional switches for the power flow control. The following assumptions are made to simplify the circuit analysis:

a. The converter is operated at the steady state.

b. The converter is operated in CCM condition.

c. The Body diodes of the power switches $S_{1}, S_{2}, S_{3}, S_{A u x 1}$, and $S_{A u x 2}$ should be considered, corresponding to diodes $D_{S 1}, D_{S 2}, D_{S 3}, D_{S A u x 1}$, and $D_{S A u x 2}$.

d. The capacitances of $C_{b a t}$ and $C_{b u s}$ are large enough to be regarded as a constant voltage source.

e. The other components are assumed with ideal conditions except for the components indicated above.

There are two operation modes when the proposed converter is analyzed in the CCM condition. The simulated waveforms of the step-up mode are shown in Figure 3 and the waveforms of the step-down mode are shown in Figure 4.

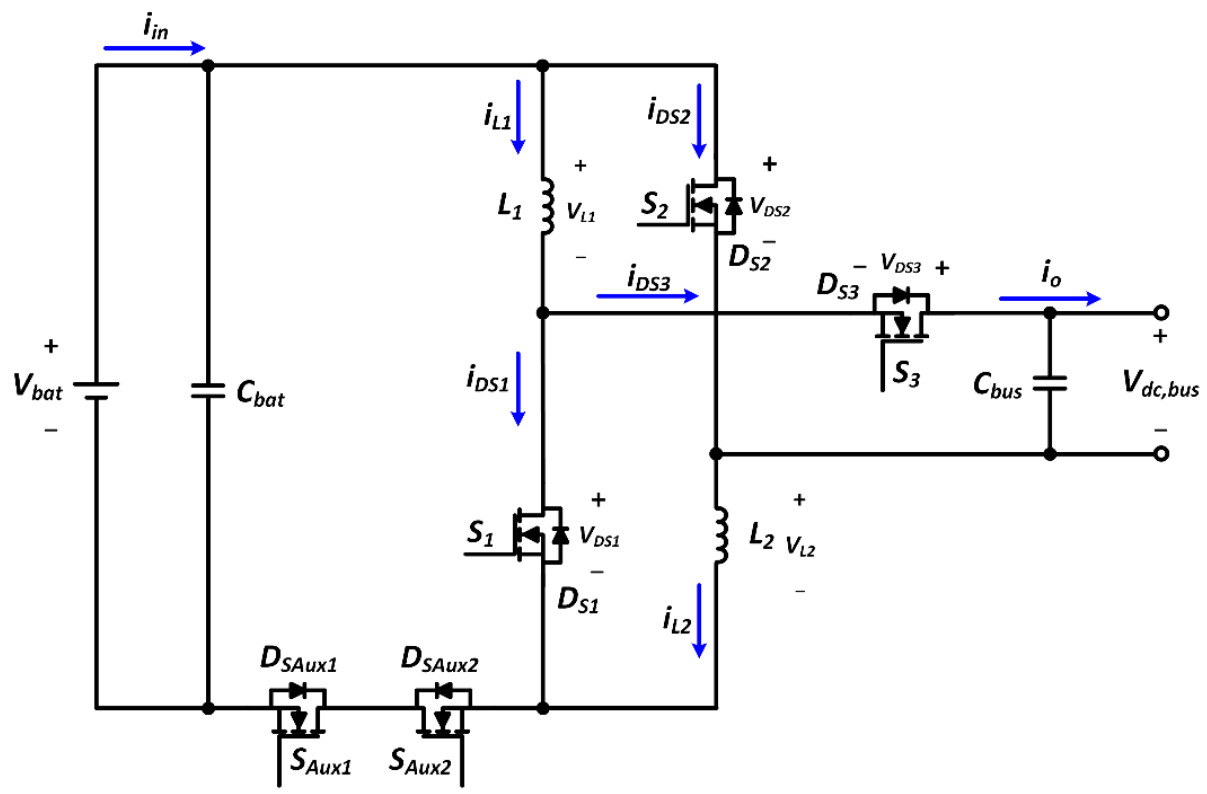

Figure 2. The topology of the proposed bidirectional DC-DC converter.

\subsection{Step-Up Mode}

\subsubsection{Mode I $\left(t_{0}-t_{1}\right)$}

At time $t_{0}$, when the switches $S_{1}$ and $S_{2}$ are turned on, the switch $S_{3}$ is turned off. Figure 5 shows the current flowing paths of this mode. The inductors $L_{1}$ and $L_{2}$ are charged by battery voltage $V_{b a t}$. This results in the inductor currents $i_{L 1}$ and $i_{L 2}$ to be linearly increased. The output capacitor $C_{b u s}$ provides energy to load $R_{\text {load }}$. The $v_{L 1}$ and $v_{L 2}$ are the voltage across the inductors $L_{1}$ and $L_{2}$, which can be represented as the Equation (1). During this interval, the rate of change in $i_{L 1}$ and $i_{L 2}$ can be derived from both Equations (2) and (3).

$$
\begin{gathered}
v_{L 1}=v_{L 2}=V_{b a t} \\
\Delta i_{L 1}{ }^{I}=\frac{\left|v_{L 1}\right|}{L_{1}}\left(t_{1}-t_{0}\right)=\frac{V_{b a t}}{L} D_{d i s} T_{s} \\
\Delta i_{L 2}{ }^{I}=\frac{\left|v_{L 2}\right|}{L_{2}}\left(t_{1}-t_{0}\right)=\frac{V_{b a t}}{L} D_{d i s} T_{S}
\end{gathered}
$$


where $\Delta i_{L 1}{ }^{I}$ is the current ripple of the inductor $L_{1}$ during mode I, $\Delta i_{L 2}{ }^{I}$ is the current ripple of the inductor $L_{2}$ during mode $I$, and $D_{d i s}$ is the duty ratio of step-up mode.

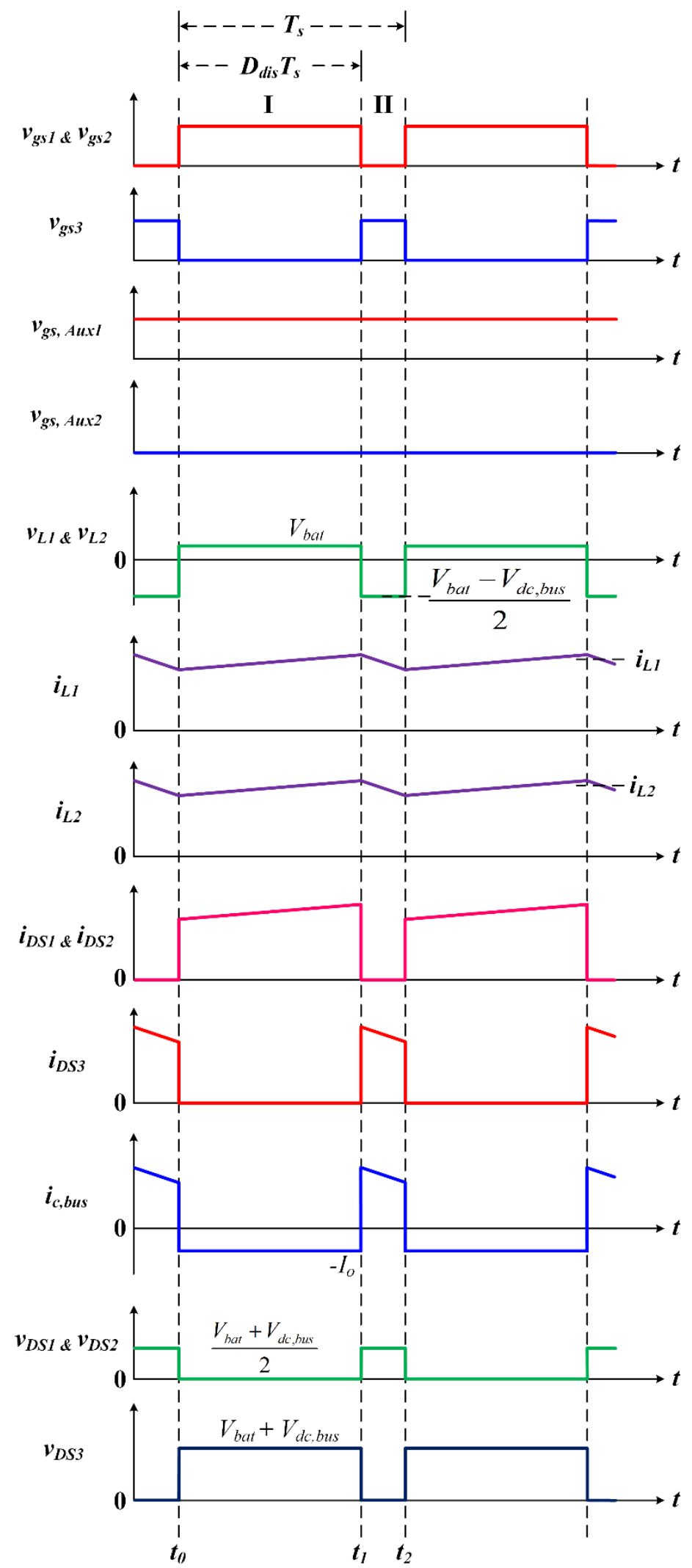

Figure 3. The waveforms of the step-up mode. 


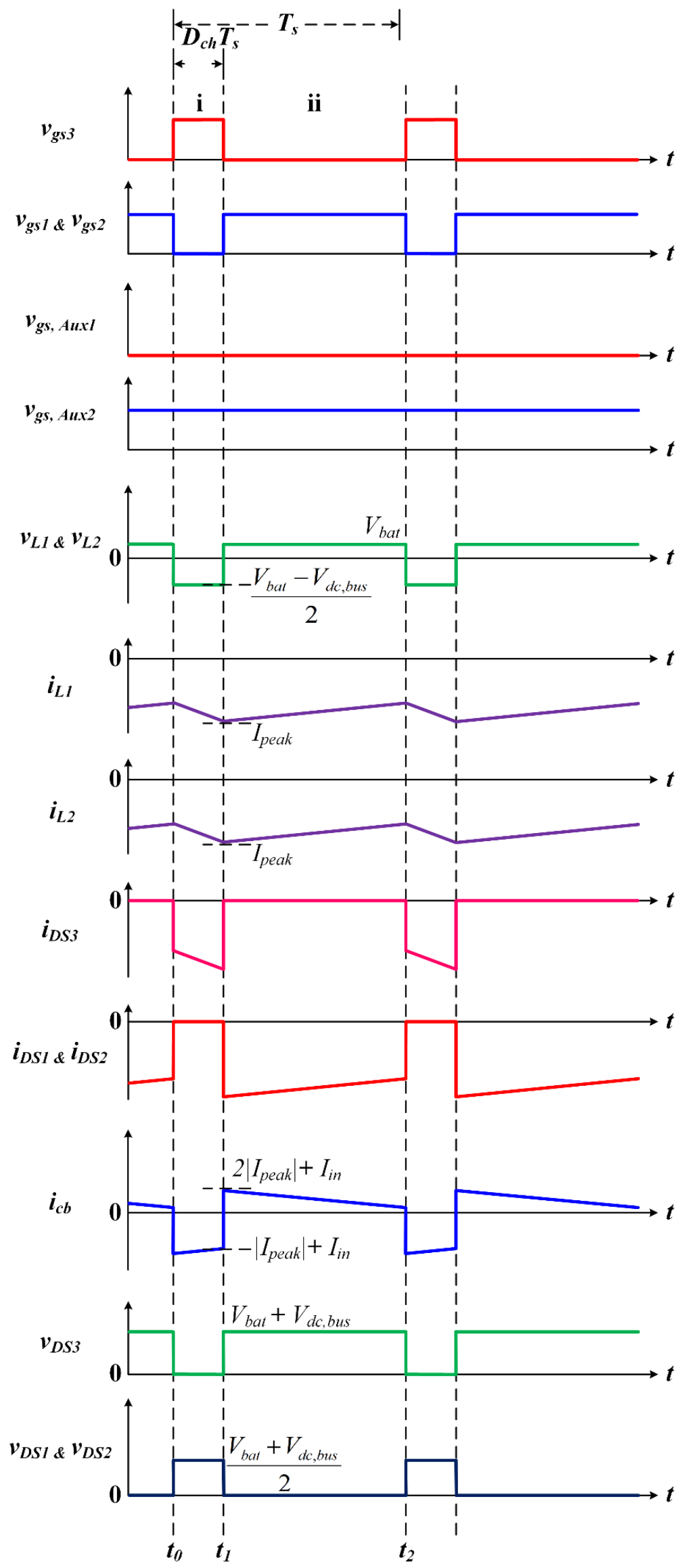

Figure 4. The waveforms of the step-down mode. 


\subsubsection{Mode II $\left(\mathrm{t}_{1}-\mathrm{t}_{2}\right)$}

At time $t_{1}$, when the switch $S_{3}$ is turned on, the switches $S_{1}$ and $S_{2}$ are turned off. The current flowing paths of this mode are shown in Figure 6. The battery voltage $V_{b a t}$ and the stored energies in the inductors $L_{1}$ and $L_{2}$ begin to charge to the output capacitor $C_{b u s}$ and transfer energy to the load $R_{\text {load }}$. The inductor currents $i_{L 1}$ and $i_{L 2}$ are linearly decreased during this period. The voltage across the inductors $v_{L 1}$ and $v_{L 2}$ can be represented as Equation (4). During this interval, the rate of change in $i_{L 1}$ and $i_{L 2}$ can be represented as Equations (5) and (6).

$$
\begin{gathered}
v_{L 1}=v_{L 2}=\frac{V_{b a t}-V_{d c, b u s}}{2} \\
\Delta i_{L 1}{ }^{I I}=\frac{\left|v_{L 1}\right|}{L_{1}}\left(t_{2}-t_{1}\right)=\frac{V_{d c, b u s}-V_{b a t}}{2 L}\left(1-D_{d i s}\right) T_{s} \\
\Delta i_{L 2}{ }^{I I}=\frac{\left|v_{L 2}\right|}{L_{2}}\left(t_{2}-t_{1}\right)=\frac{V_{d c, b u s}-V_{b a t}}{2 L}\left(1-D_{d i s}\right) T_{S}
\end{gathered}
$$

where $\Delta i_{L 1}{ }^{I I}$ is the current ripple of the inductor $L_{1}$ during mode II, $\Delta i_{L 2}{ }^{I I}$ is the current ripple of the inductor $L_{2}$ during mode II, and $D_{d i s}$ is the duty ratio of step-up mode.

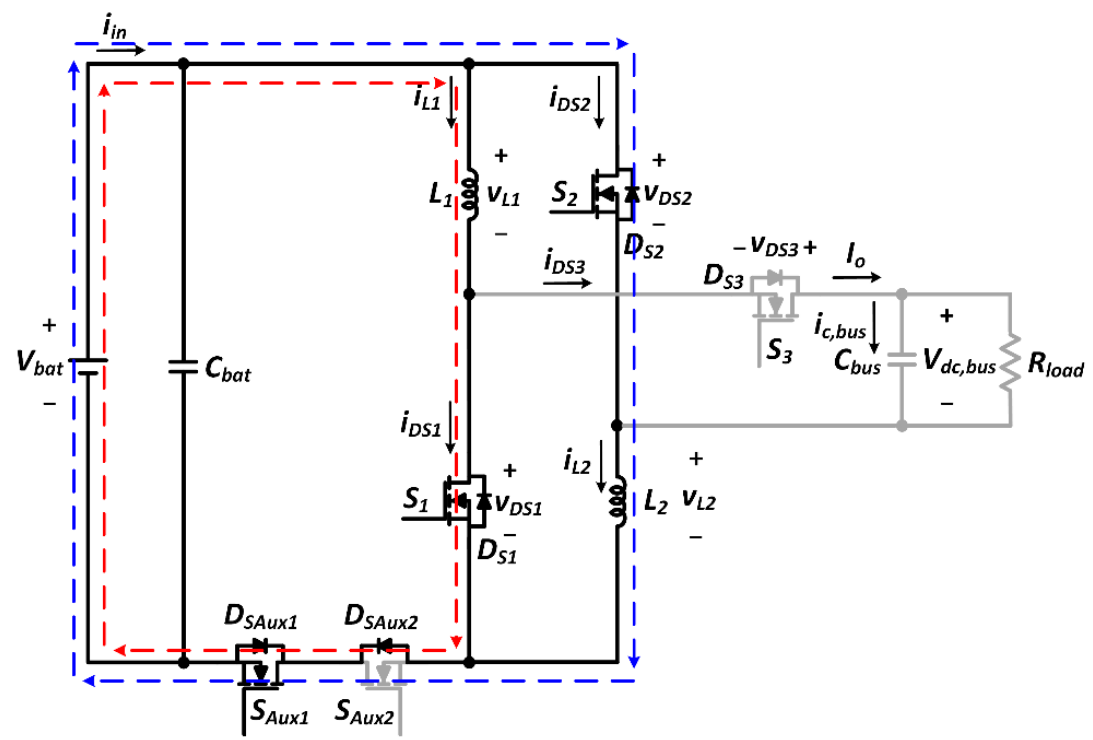

Figure 5. The current flow paths of step-up Mode I.

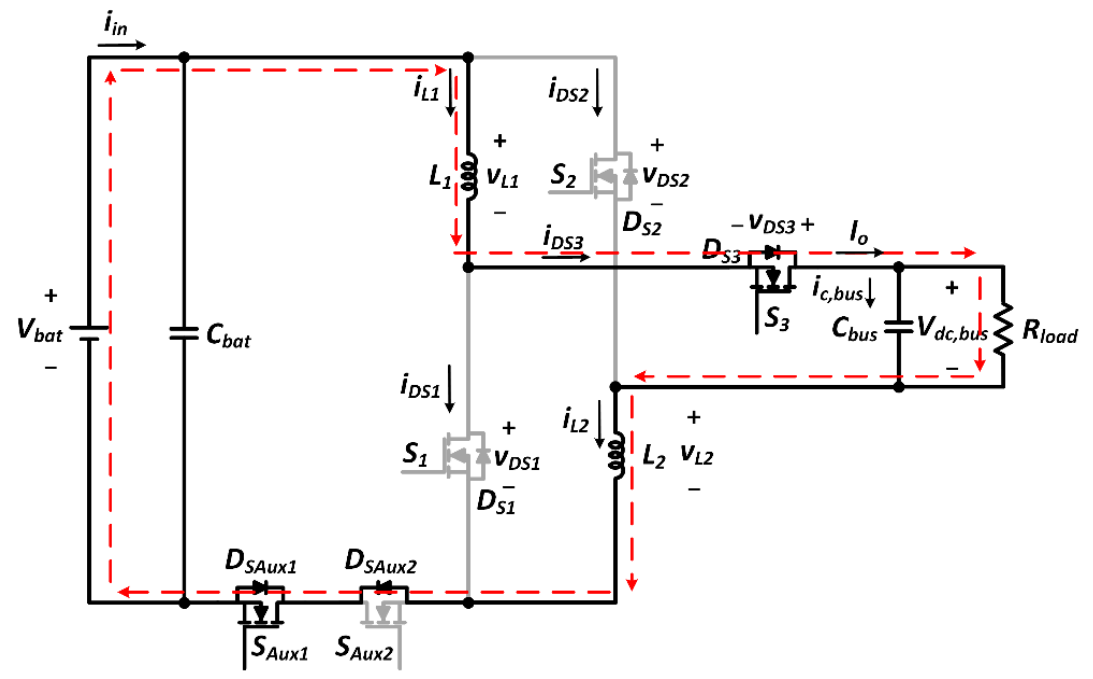

Figure 6. The current flow paths of step-up mode II. 


\subsection{Step-Down Mode}

\subsubsection{Mode i $\left(t_{0}-t_{1}\right)$}

At time $t_{0}$, when the switch $S_{3}$ is turned on, the switches $S_{1}$ and $S_{2}$ are turned off. The current flowing paths of mode $i$ are shown in Figure 7 . In this mode, the inductors $L_{1}$, $L_{2}$, and the capacitor $C_{b a t}$ are charged in series by DC bus voltage $V_{d c, b u s}$. Therefore, the inductor currents $i_{L 1}, i_{L 2}$ are linearly decreased.

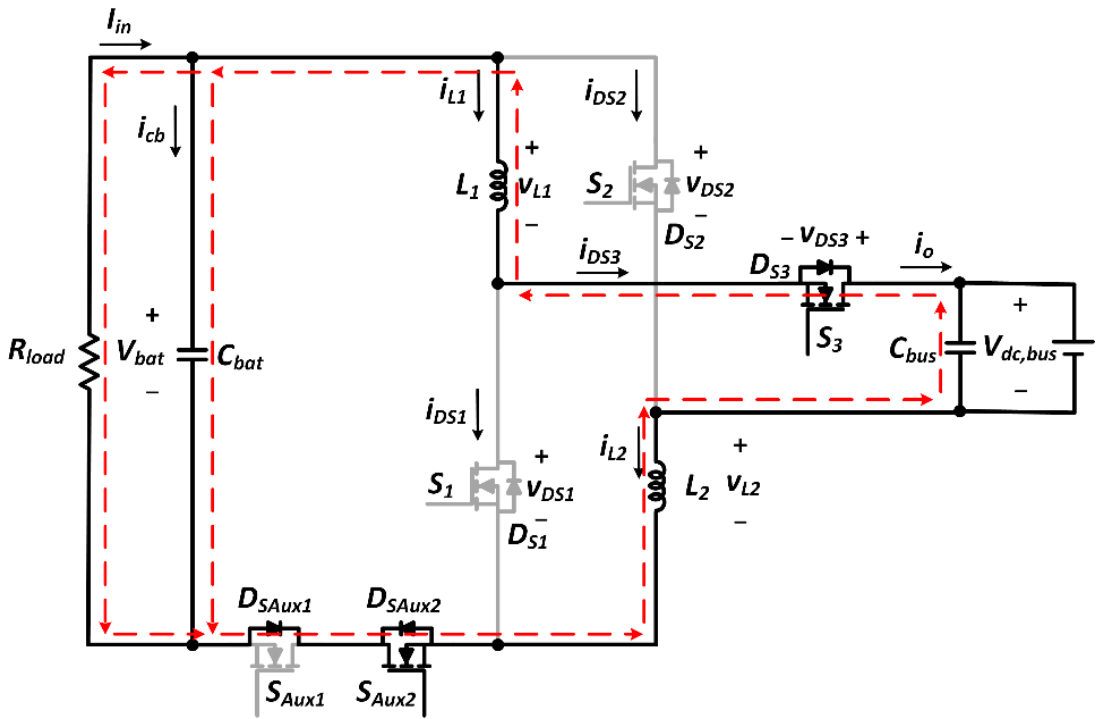

Figure 7. The current flow paths of step-down mode i.

\subsubsection{Mode ii $\left(t_{1}-t_{2}\right)$}

At time $t_{1}$, when the switch $S_{3}$ is turned off, the switches $S_{1}$ and $S_{2}$ are turned on. The current flowing paths of mode ii are shown in Figure 8. In this mode, the inductors $L_{1}$, $L_{2}$, and the capacitor $C_{b a t}$ release energies to the battery voltage $V_{b a t}$. This results in the inductor currents $i_{L 1}$ and $i_{L 2}$ to be linearly increased.

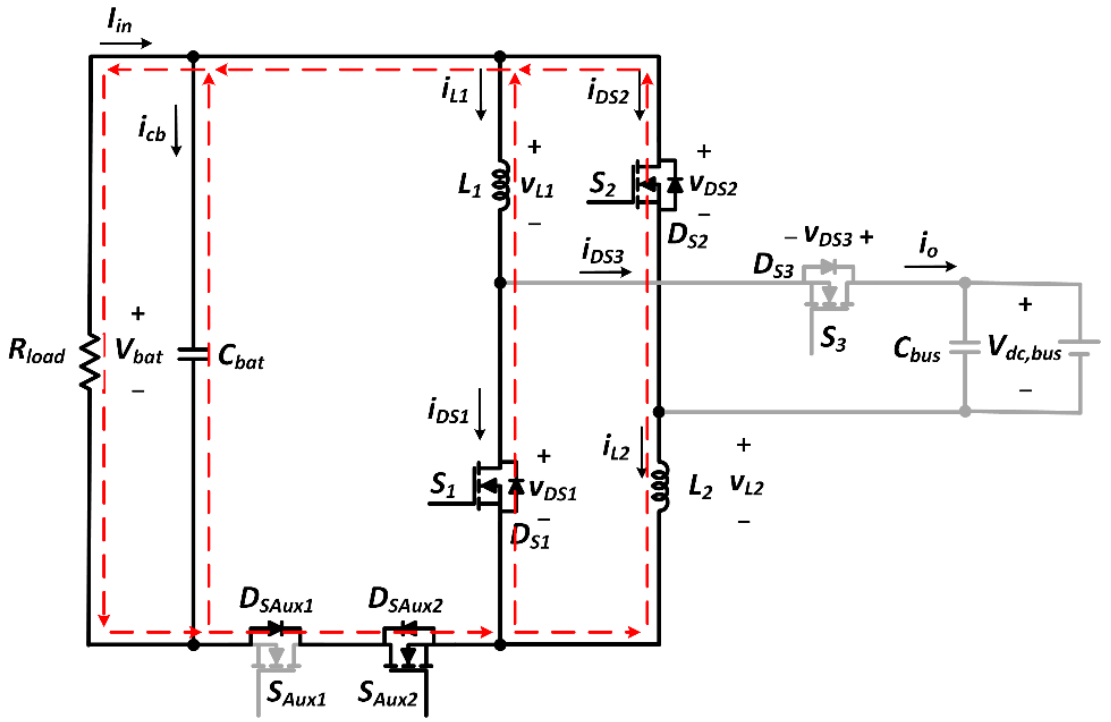

Figure 8. The current flow paths of step-down mode ii.

According to the voltage-second balance principle, the average voltage on inductors $L_{1}$ and $L_{2}$ in one switching cycle is zero. This can be expressed as Equations (7) and (8). 


$$
\begin{aligned}
& \frac{1}{T_{S}} \int_{0}^{T_{S}} v_{L 1} d t=0 \Rightarrow \int_{0}^{t_{1}} v_{L 1} d t+\int_{t_{1}}^{t_{2}} v_{L 1} d t=0 \\
& \frac{1}{T_{S}} \int_{0}^{T_{S}} v_{L 2} d t=0 \Rightarrow \int_{0}^{t_{1}} v_{L 2} d t+\int_{t_{1}}^{t_{2}} v_{L 2} d t=0
\end{aligned}
$$

Based on Equations (1) and (4), the Equations (7) and (8) can be simplified as Equation (9):

$$
V_{b a t} D_{d i s} T_{s}+\frac{V_{b a t}-V_{d c, b u s}}{2}\left(1-D_{d i s}\right) T_{s}=0,
$$

The voltage conversion ratio of the step-up mode can be derived as Equation (10). Similarly, the voltage conversion ratio of the step-down mode can use the same approach to derive as Equation (11).

$$
\begin{aligned}
& \frac{V_{d c, b u s}}{V_{b a t}}=\frac{1+D_{d i s}}{1-D_{d i s}}, \\
& \frac{V_{b a t}}{V_{d c, b u s}}=\frac{D_{c h}}{2-D_{c h}} .
\end{aligned}
$$

where $D_{\text {dis }}$ is the duty ratio of the step-up mode, and $D_{c h}$ is the duty ratio of the step-down mode.

\section{Control Strategy of Transferring State}

In this section, the transferring states from step-up mode to step-down mode and vice versa are described in detail. The direction of all energy storage components in the circuit must be considered carefully because the direction of the inductor current or capacitor voltage cannot be reversed immediately.

To achieve the power flow control of the bidirectional converter, it is necessary to execute the following steps:

Step 1: Detect the status of the transfer signal and determine whether the converter changes the operating mode or not.

Step 2: The gate driving signals of the bidirectional switches $S_{A u x 1}$ and $S_{A u x 2}$ maintain the original operating mode until the inductor currents $i_{L 1}$ and $i_{L 2}$ demagnetize to zero.

Step 3: The gate driving signals of the bidirectional switches $S_{A u x 1}$ and $S_{A u x 2}$ change the original operating mode.

Step 4: Finally, restore the gate driving signals of the main switches $S_{1}, S_{2}$, and $S_{3}$.

\subsection{Transferring State from Step-Up Mode to Step-Down Mode}

For the converters operating in CCM condition, the driving signals of all the power switches during the transferring state are shown in Figure 9, illustrating the procedure of the transferring state, and the timing of the transferring state occurring from mode II of the step-up mode to mode $\mathrm{i}$ of the step-down mode. For the converters operating in BCM or DCM conditions, the transfer state occurs when the inductor current reaches zero.

During the transferring stage, the switch $S_{3}$ is turned on for a switching cycle to provide a path for the freewheeling of the inductor current. The inductor currents $i_{L 1}$ and $i_{L 2}$ are linearly decreased until the inductor currents demagnetize to zero. The original operating mode of the bidirectional switches $S_{A u x 1}$ and $S_{A u x 2}$ is changed. After time $t_{2}$, the gate driving signals of the main switches $S_{1}, S_{2}$, and $S_{3}$ are restored, and the circuit enters into the step-down mode. This results in the inductors $L_{1}$ and $L_{2}$ beginning to store the energy.

\subsection{Transferring State from Step-Down Mode to Step-Up Mode}

For converters operating in CCM condition, the gate driving signals of all the power switches during the transferring state are shown in Figure 10, illustrating the procedure of the transferring state and the timing of the transferring state occurring from mode II of the step-up mode to mode i of the step-down mode. For the converters operating in BCM or DCM conditions, the transfer state occurs when the inductor current reaches zero. 
During the transferring stage, the switch $S_{3}$ is turned off and the bidirectional switches $S_{A u x 1}$ and $S_{A u x 2}$ remain in the original operating mode. The switches $S_{1}$ and $S_{2}$ are then turned on for two switching cycles to provide a path for the freewheeling of the inductor current. The inductor currents $i_{L 1}$ and $i_{L 2}$ are linearly increased until the inductor currents demagnetize to zero. The original operating mode of the bidirectional switches $S_{A u x 1}$ and $S_{A u \times 2}$ is changed. After time $t_{3}$, the gate driving signals of the main switches $S_{1}, S_{2}$, and $S_{3}$ are restored, and the circuit enters the step-up mode. This results in the inductors $L_{1}$ and $L_{2}$ beginning to store energy.

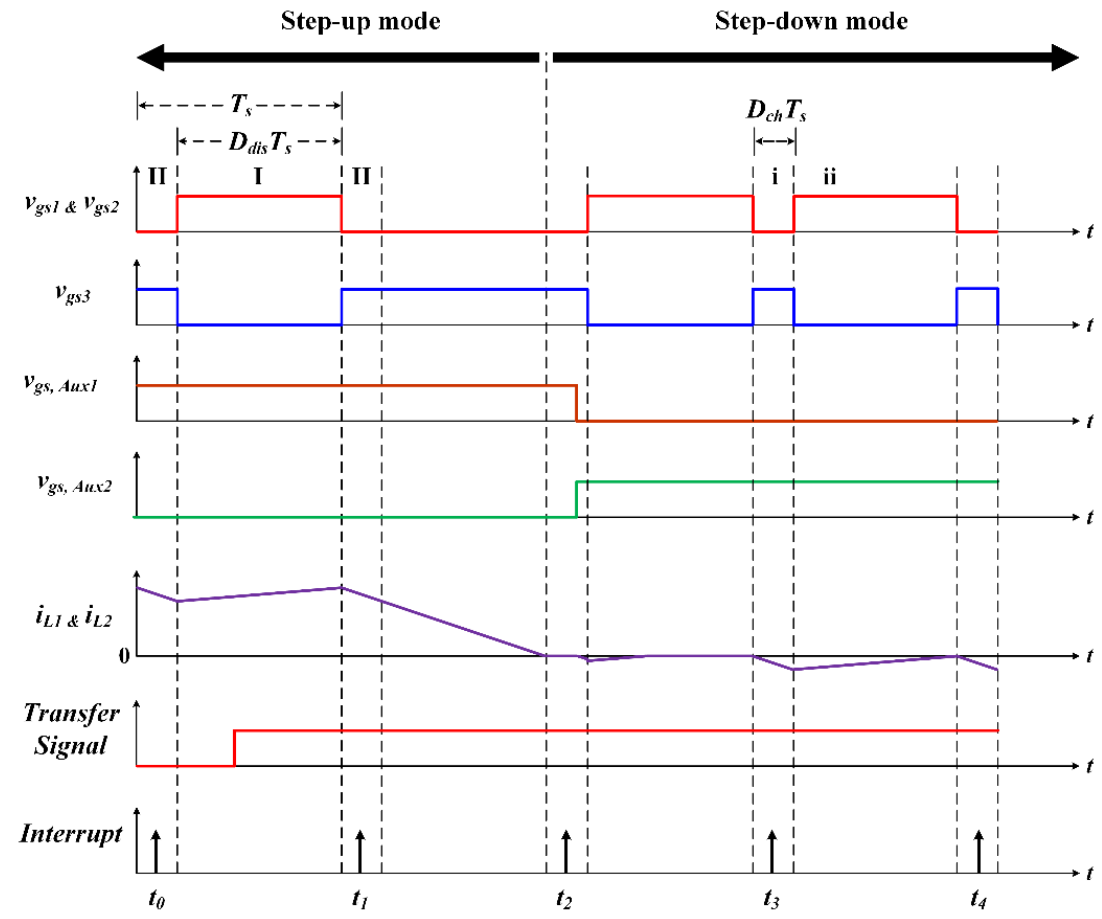

Figure 9. The timing of the transferring state from step-up mode to step-down mode.

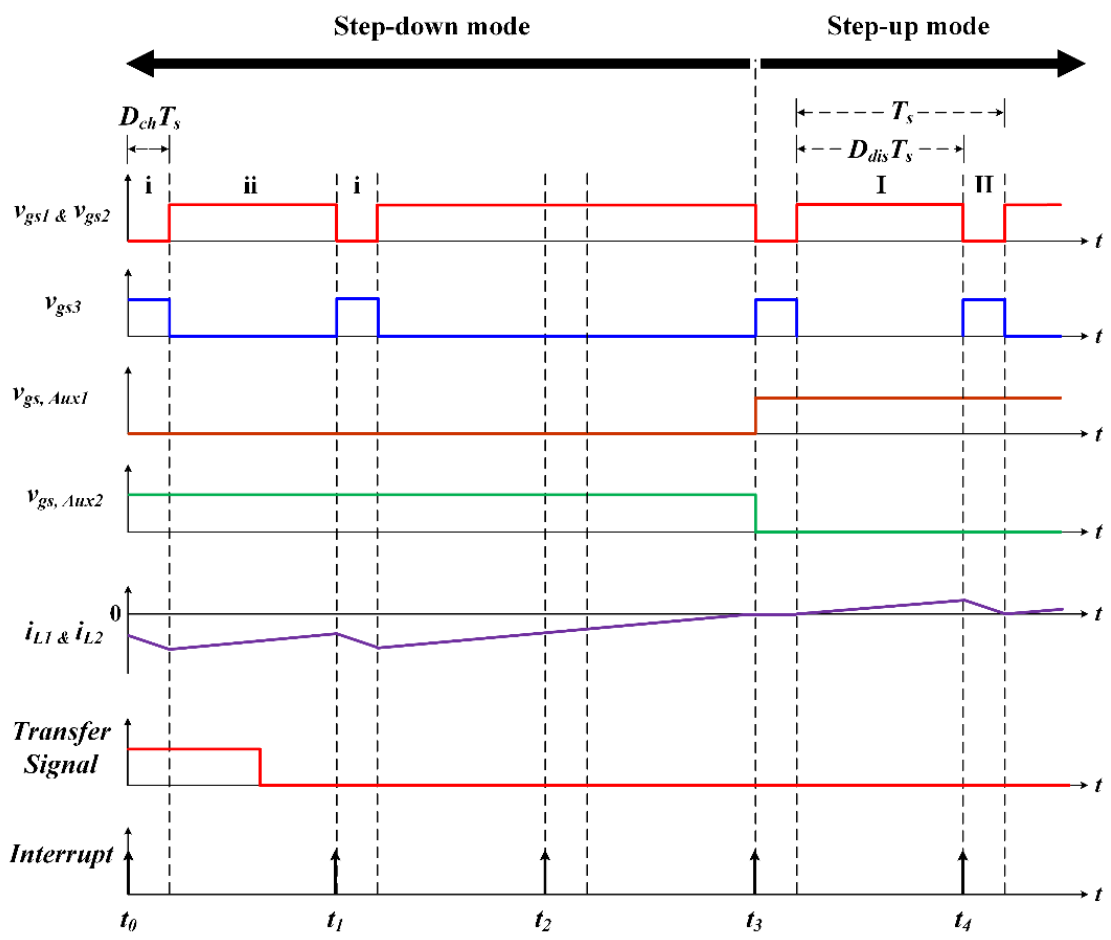

Figure 10. Timing of the transferring state from step-down mode to step-up mode. 


\subsection{Flow Chart of the Digital Control System}

In general, the digital control program can be divided into the main program and the interrupt subroutine. The purpose of the main program is to configure system parameters, declare variables, and arrange the subroutines in order. In addition, the interrupt subroutine is not executed until the interrupt event occurs. The interrupt subroutine is used to evaluate events and perform complex calculations.

The flow chart of the main program is shown in Figure 11. The system parameters are first initialized at the beginning of the program and the function blocks of $\mathrm{MCU}$, such as I/O pins of GPIO modules, ADC modules, and pulse width modulation (PWM) modules, are then configured. Finally, the trigger condition of the interrupt register is configured.

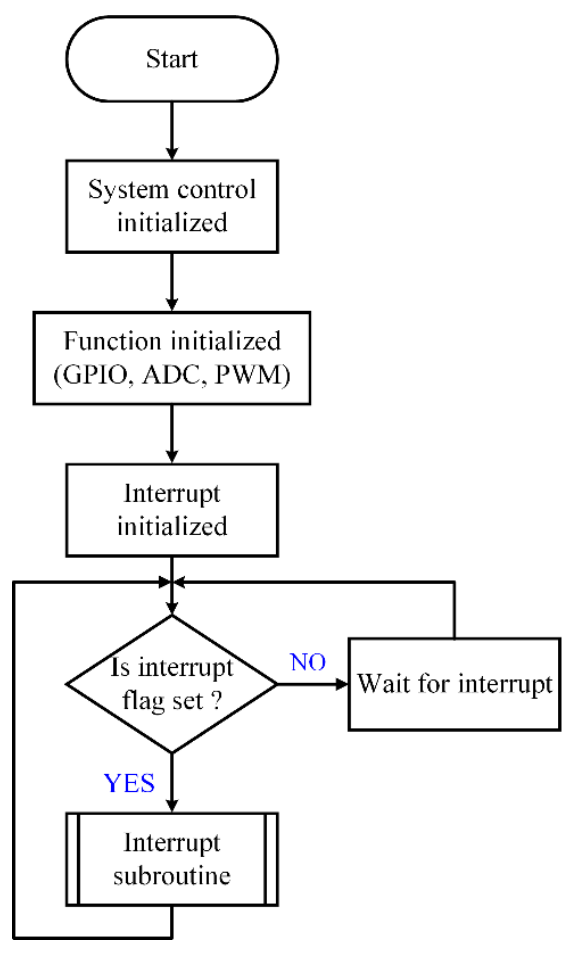

Figure 11. Flow chart of the main program.

The flow chart of the interrupt subroutine is shown in Figure 12. For the power flow control of the bidirectional converter to work, the following procedures should be made:

1. If the time-base counter operates in the up-count mode and the initial value of the counter is zero, the counter value increases until the PRD value is reached. The time-based counter is then reset to zero and then recount from zero to PRD value again. The cycle period of the count value is equivalent to one system cycle.

2. When the time-base counter equals zero, this event sets the flag of interrupt and enters the interrupt service routine. In addition, the ADC module is also e = set to perform the conversion.

3. After entering the interrupt service routine, the flag of interrupt must be cleared first so that the interrupt subroutine can be executed next time.

4. Finally, the state of the transfer signal is detected to determine at which mode the converter is operating. If the transfer signal is detected as 0 , the converter operates in the discharging mode. On contrary, if the transfer signal is detected as 1 , the converter operates in the charging mode. 


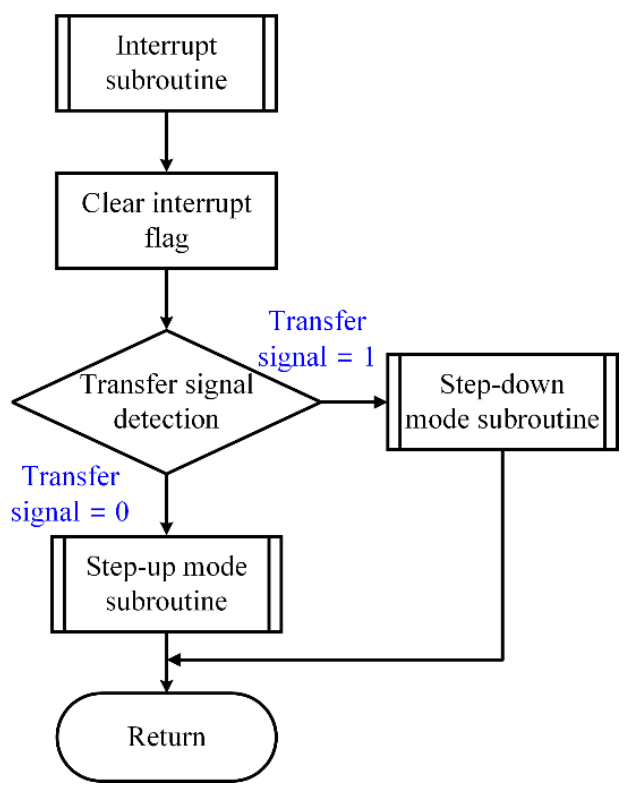

Figure 12. Flow chart of the interrupt subroutine.

After entering the interrupt service routine, the transfer signal is determined by the DSP. When the transfer signal is detected as 0 , the converter operates in the step-up mode. On contrary, when the transfer signal is detected as 1, the converter operates in the stepdown mode. In addition, the feedback circuits detect the values of the battery voltage and the DC bus voltage for voltage regulation. Finally, before leaving the interruption, the flag of interruption is cleared for the next interruption to occur. The block diagram of the control strategy is shown in Figure 13.

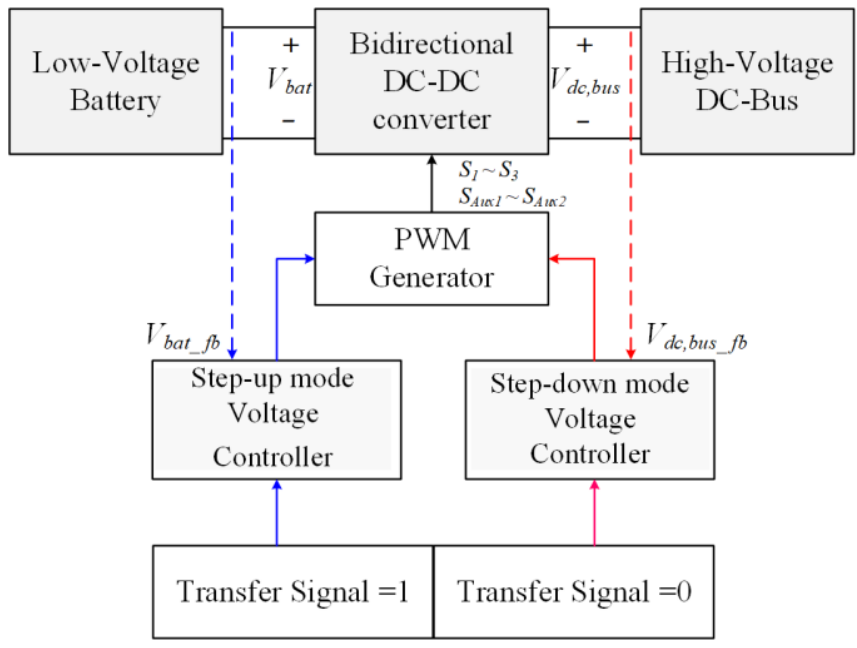

Figure 13. Block diagram of the control strategy.

\section{Experimental Results}

The experimental system consists of a bidirectional DC-DC converter and a DSPbased digital compensator, as shown in Figure 14. The bidirectional DC-DC converter is implemented with a battery voltage of $24 \mathrm{~V}$, and a $200 \mathrm{~V} \mathrm{DC}$ bus voltage. The related specifications are listed in Tables 1 and 2. 

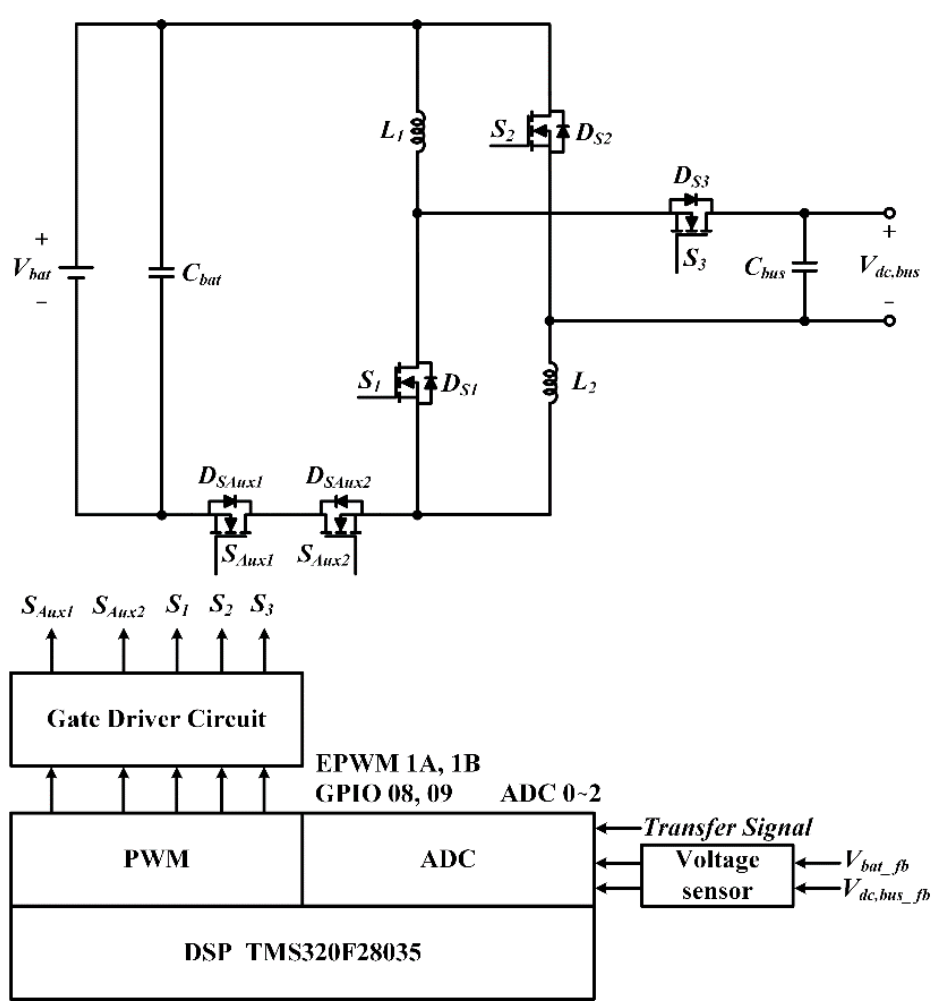

Figure 14. Block diagram of the experimental system for bidirectional power flow control.

Table 1. Specifications of the experimental system.

\begin{tabular}{cccc}
\hline \multicolumn{2}{c}{ Step-Up Mode } & \multicolumn{2}{c}{ Step-Down Mode } \\
\hline Battery Voltage, $V_{b a t}$ & $24 \mathrm{~V}$ & DC Bus Voltage, $V_{d c}, b u s$ & $200 \mathrm{~V}$ \\
DC Bus Voltage, $V_{d c, b u s}$ & $200 \mathrm{~V}$ & Battery Voltage, $V_{b a t}$ & $24 \mathrm{~V}$ \\
Step-up Power, $P_{d i s}$ & $500 \mathrm{~W}$ & Step-down Power, $P_{b}$ & $500 \mathrm{~W}$ \\
Switching Frequency, $f_{s 1}$ & $50 \mathrm{kHz}$ & Switching Frequency, $f_{s 2}$ & $50 \mathrm{kHz}$ \\
\hline
\end{tabular}

Table 2. Parameters of the experimental system.

\begin{tabular}{cc}
\hline Item & Value \\
\hline Inductors $L_{1}, L_{2}$ & $185 \mu \mathrm{H}$ \\
Capacitor $C_{\text {bat }}$ & $56 \mu \mathrm{F} / 35 \mathrm{~V}$ \\
Capacitor $C_{d c}$, bus & $22 \mu \mathrm{F} / 250 \mathrm{~V}$ \\
Main Switches $S_{1}, S_{2}, S_{3}$ & IMW65R048M1H \\
Bidirectional Switches $S_{\text {Aux } 1}, S_{\text {Aux } 2}$ & FDH055N15A \\
\hline
\end{tabular}

The hardware circuit of the proposed converter is shown in Figure 15, which is composed of synchronous rectification switches and bidirectional switches. The DSP is used to provide synchronous control and power flow control in the bidirectional DC-DC converter.

\subsection{Step-Up Mode to Step-Down Mode (CCM Condition)}

The experimental waveforms with 50\% load condition are shown in Figure 16. The gate driving signals $v_{g s 1}$ and $v_{g s 2}$ are complementary to the gate driving signal $v_{g s 3}$. Moreover, the gate driving signal $v_{g s, A u x 1}$ is complementary to the gate driving signal $v_{g s, A u x 2}$. When the transfer signal changes from 0 to 1 , the inductor currents $i_{L 1}$ and $i_{L 2}$ linearly demagnetize to zero, and the direction of the inductor currents immediately reverses to the opposite direction. Thus, the experimental results presented in Figure 16 validate that the proposed control strategy can effectively switch from the step-up mode to the step-down mode. 


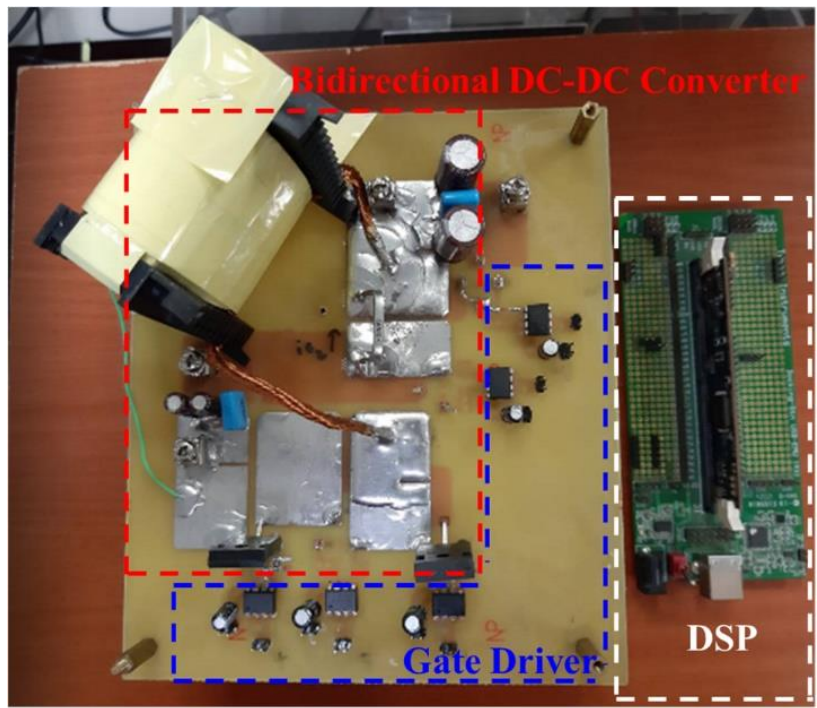

Figure 15. Photography of the experimental system.

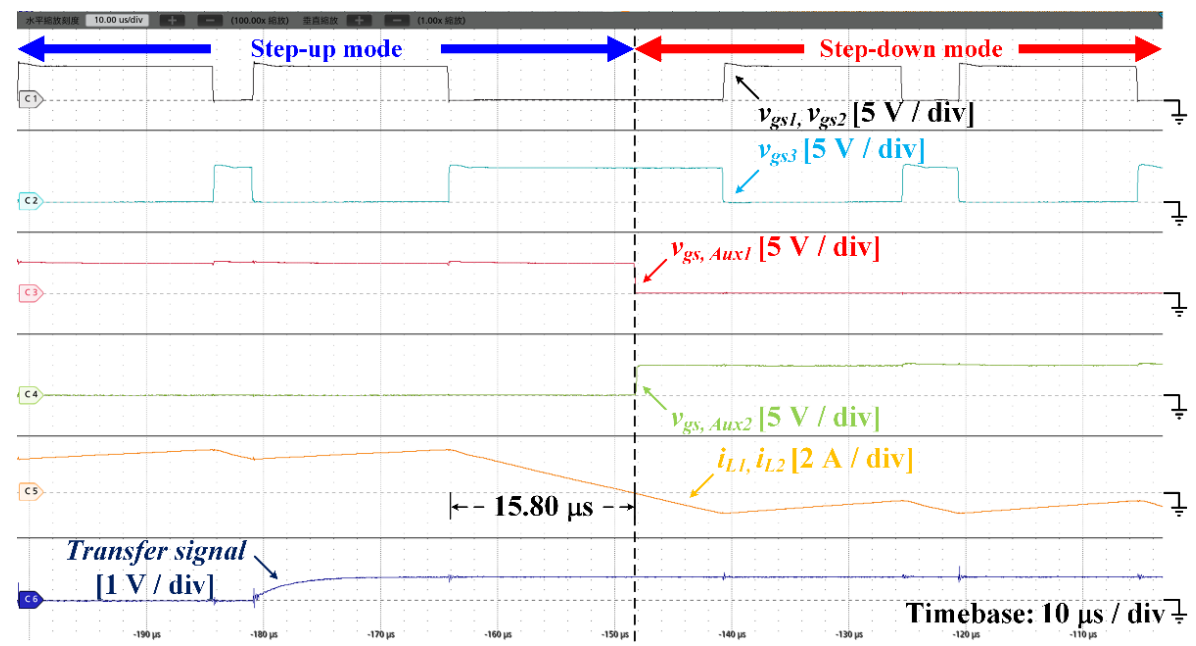

(a)

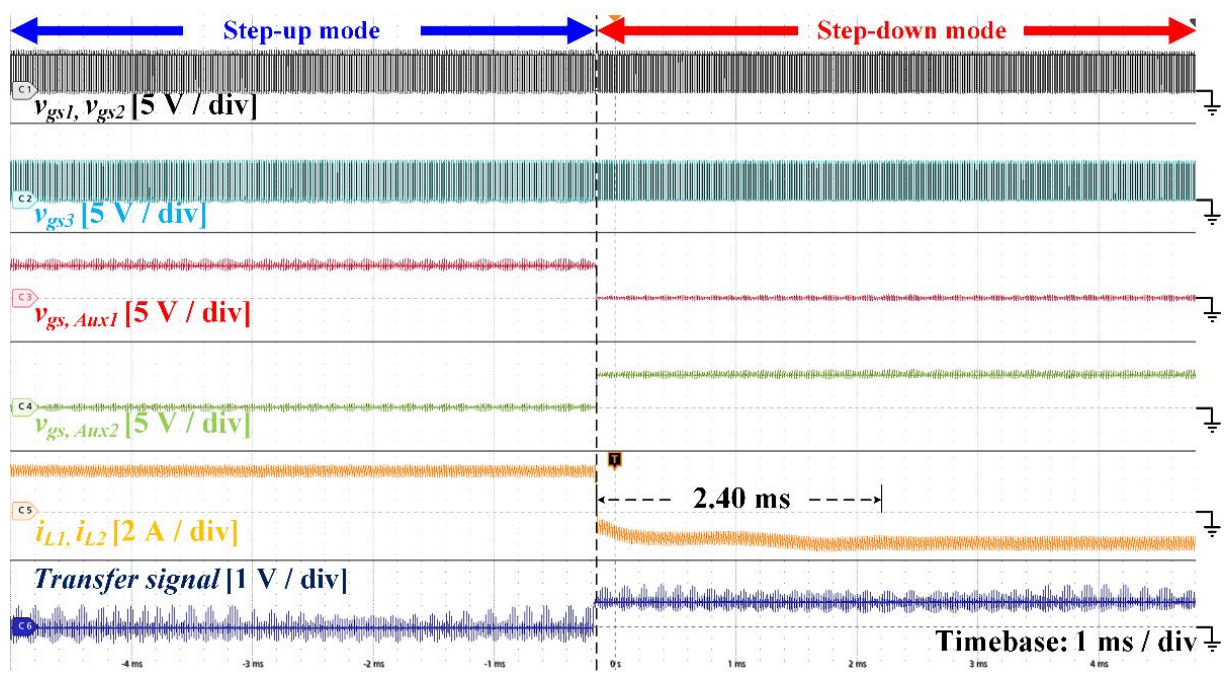

(b)

Figure 16. Waveforms of dynamic performances with $50 \%$ load condition. (a) $v_{g s 1}, v_{g s 2}, v_{g s}, v_{g s, A u x 1}$, $v_{g s, A u x 2}, i_{L 1}, i_{L 2}$, transfer signal. (b) Change from the step-up mode to the step-down mode. 


\subsection{Step-Down Mode to Step-Up Mode (CCM Condition)}

The experimental waveforms with 50\% load condition are shown in Figure 17. The gate driving signals $v_{g s 1}$ and $v_{g s 2}$ are complementary to the gate driving signal $v_{g s} 3$. Moreover, the gate driving signal $v_{g s, A u x 1}$ is complementary to the gate driving signal $v_{g s, A u x 2}$. When the transfer signal changes from 1 to 0 , the inductor currents $i_{L 1}$ and $i_{L 2}$ linearly demagnetize to zero, and the direction of the inductor currents immediately reverses to the opposite direction. The experimental results presented in Figure 17 validate that the proposed control strategy can effectively switch from the step-down mode to the step-up mode.

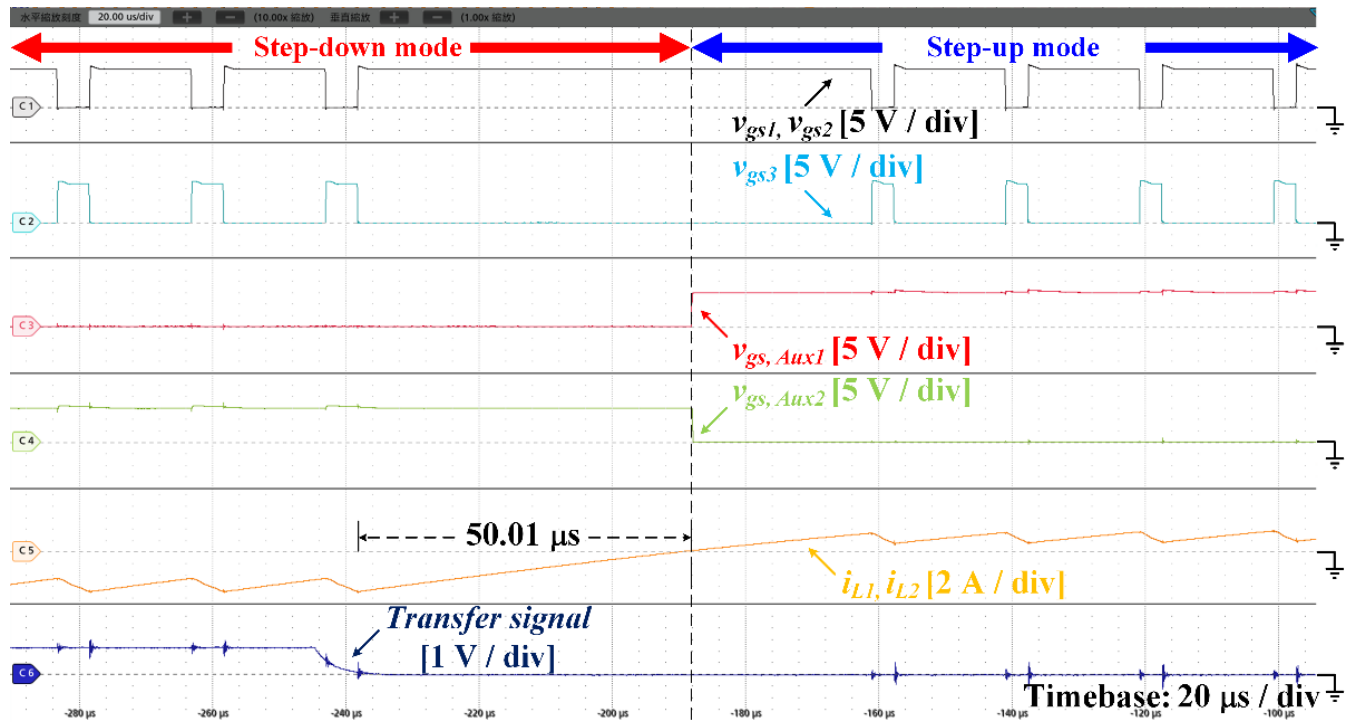

(a)

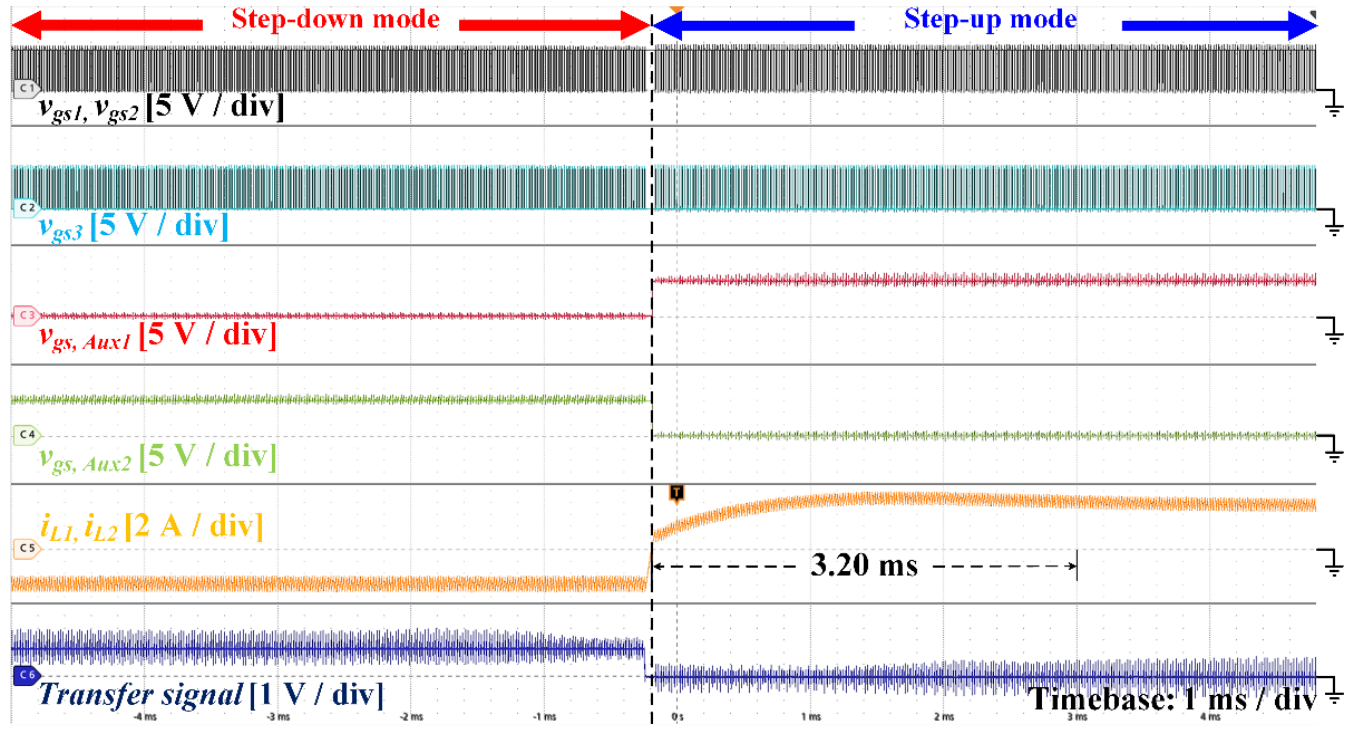

(b)

Figure 17. Waveforms of dynamic performances with $50 \%$ load condition. (a) $v_{g s 1}, v_{g s 2}, v_{g s 3}, v_{g s, A u x 1}$, $v_{g s, A u x 2}, i_{L 1}, i_{L 2}$, transfer signal. (b) Change from the step-down mode to the step-up mode.

\subsection{Step-Up Mode to Step-Down Mode (BCM Condition)}

The experimental waveforms with BCM load conditions are shown in Figure 18. The gate driving signals $v_{g s 1}$ and $v_{g s 2}$ are complementary to the gate driving signal $v_{g s}$. Moreover, the gate driving signal $v_{g s, A u x 1}$ is complementary to the gate driving signal $v_{g s, A u x 2}$. When the transfer signal changes from 0 to 1 , the inductor currents $i_{L 1}$ and 
$i_{L 2}$ linearly demagnetize to zero, and the direction of the inductor currents immediately reverses to the opposite direction. The experimental results presented in Figure 18 validate that the proposed control strategy can effectively switch from the step-up mode to the step-down mode within one switching cycle.

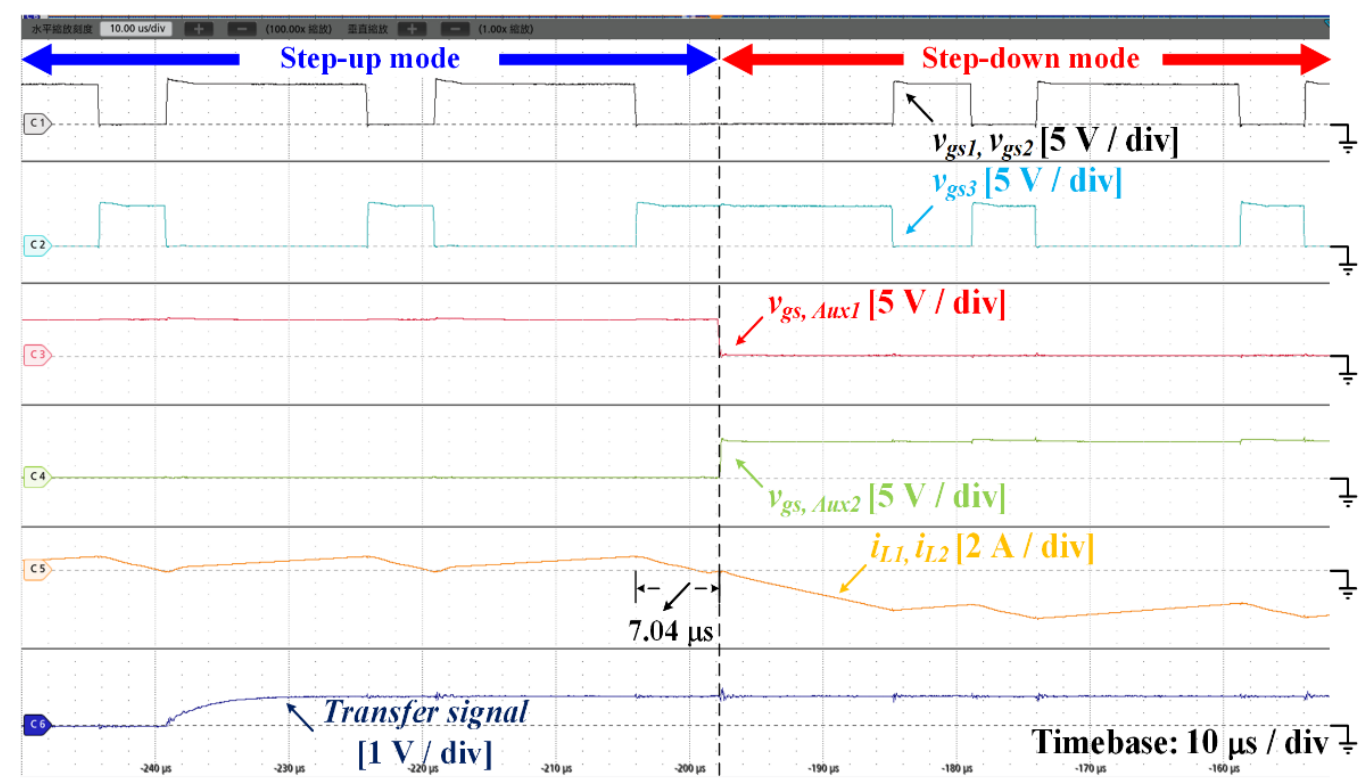

(a)

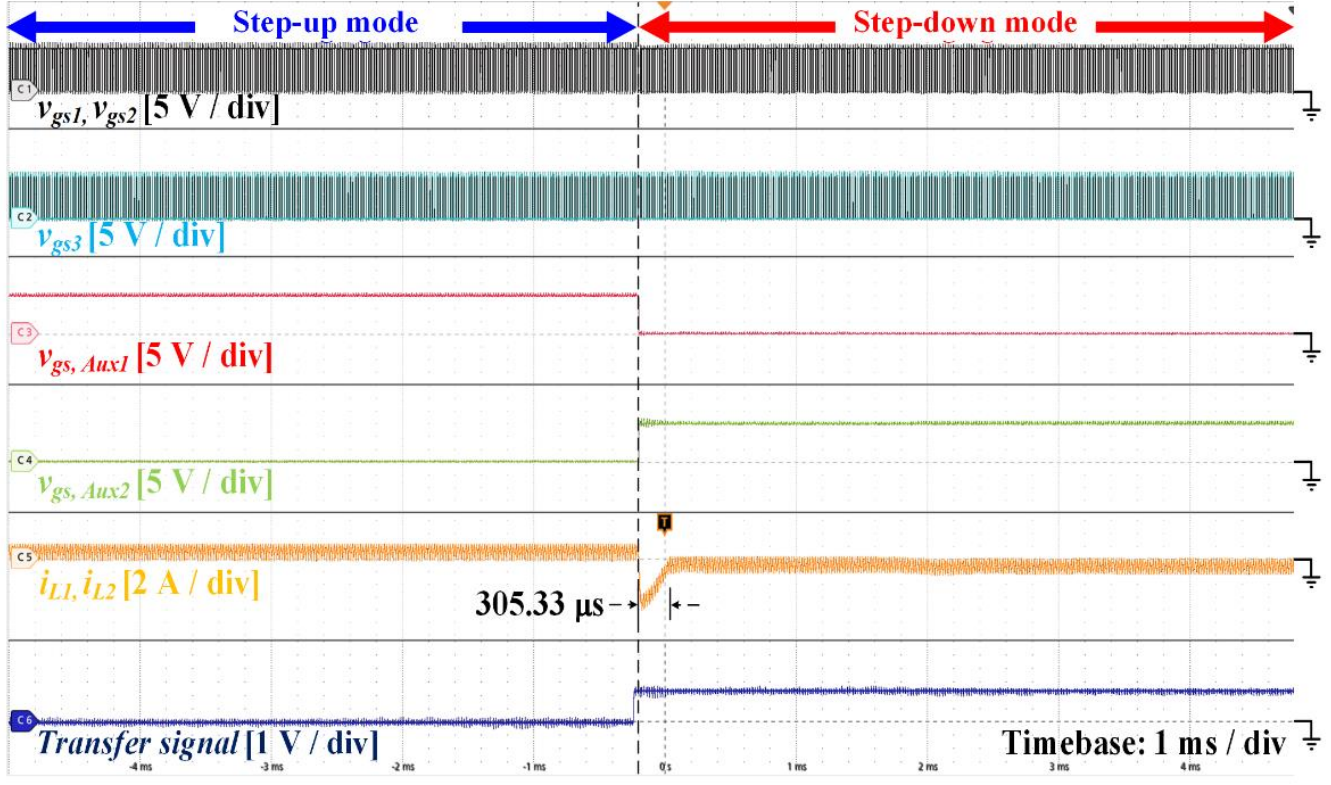

(b)

Figure 18. Experimental results of dynamic performances with BCM load condition. (a) $v_{g s 1}, v_{g s 2}, v_{g s 3}$, $v_{g s, A u x 1}, v_{g s, A u x 2}, i_{L 1}, i_{L 2}$, transfer signal. (b) Change from the step-up mode to the step-down mode.

\subsection{Step-Up Mode to Step-Down Mode (DCM Condition)}

The experimental waveforms with DCM load conditions are shown in Figure 19. The gate driving signals $v_{g s 1}$ and $v_{g s 2}$ are complementary to the gate driving signal $v_{g s 3}$. Moreover, the gate driving signal $v_{g s, A u x 1}$ is complementary to the gate driving signal $v_{g s, A u x 2}$. When the transfer signal changes from 0 to 1 , the inductor currents $i_{L 1}$ and $i_{L 2}$ linearly demagnetize to zero and then commutate immediately. The experimental results 
in Figure 19 validate that the proposed control strategy can effectively switch from the step-up mode to the step-down mode within one switching cycle.

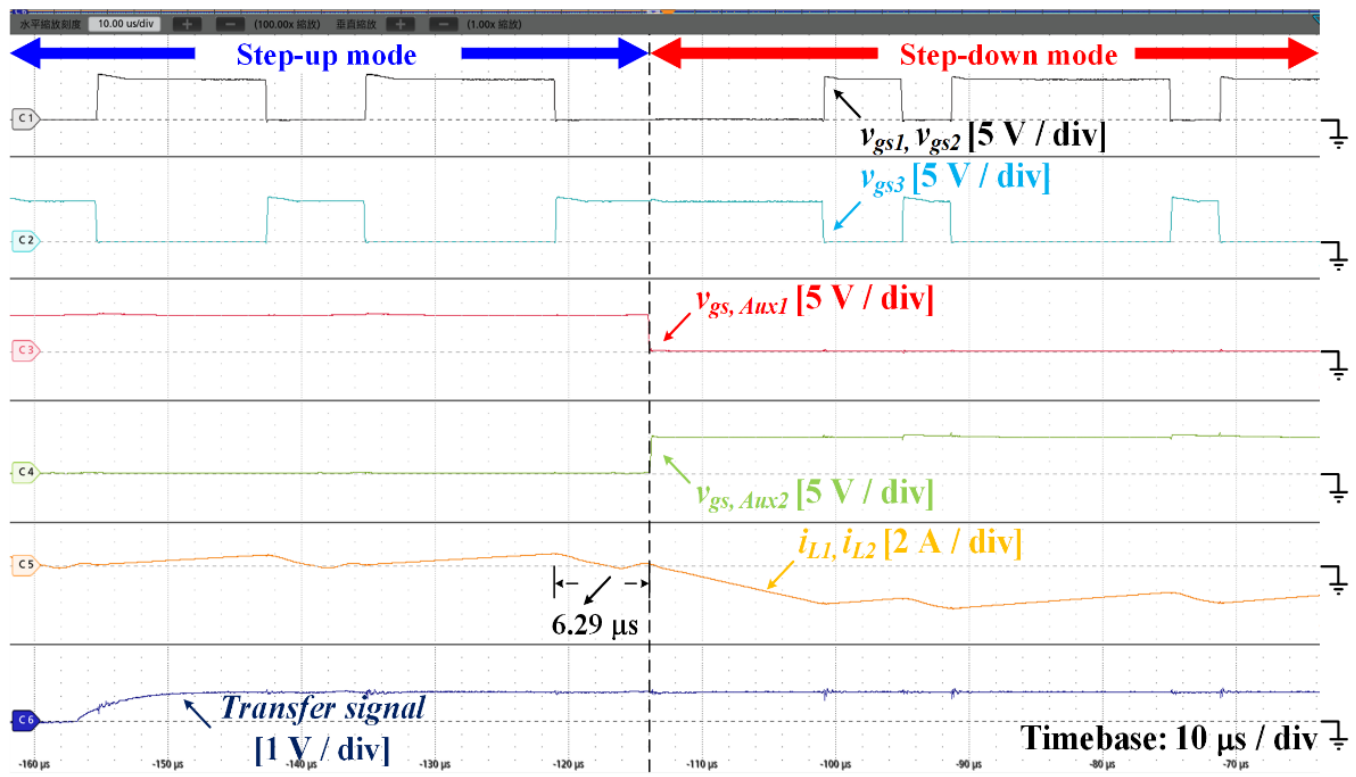

(a)

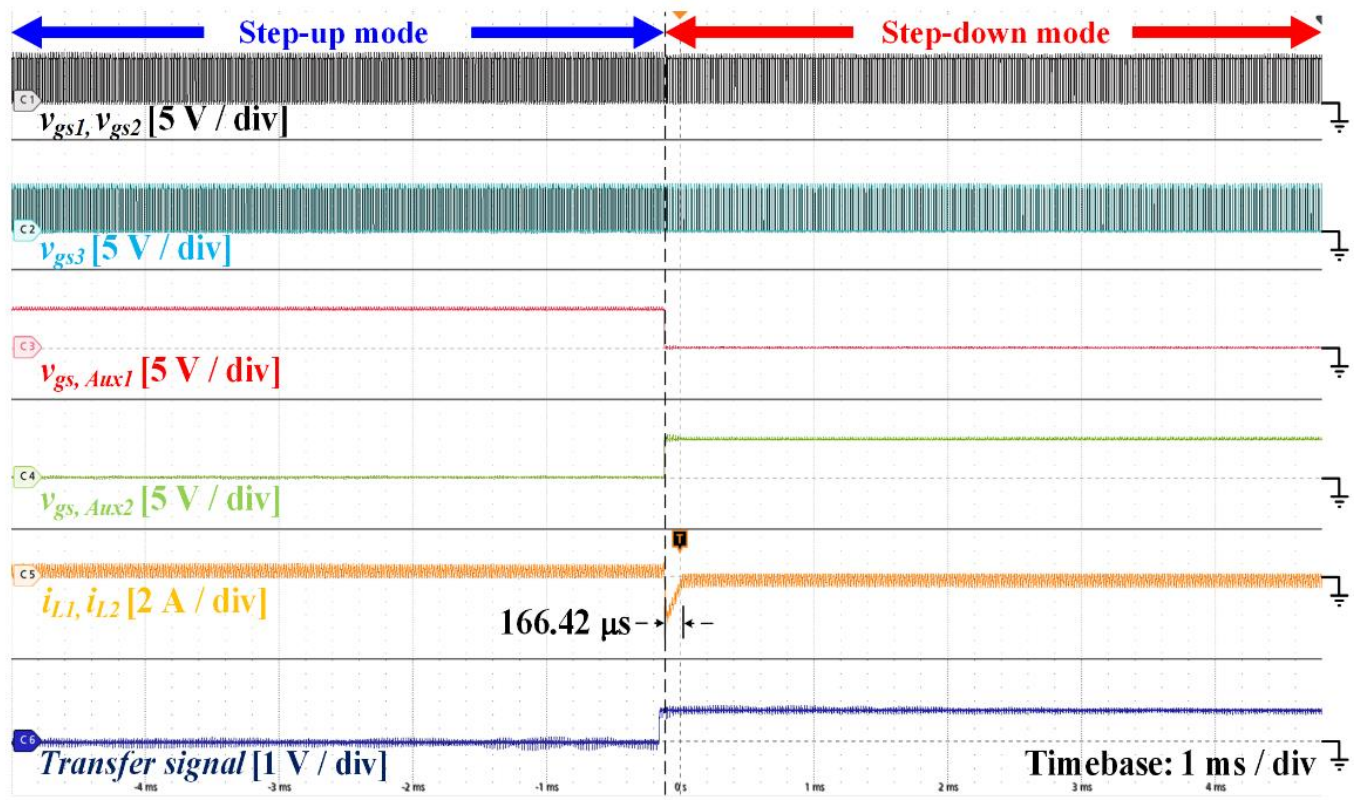

(b)

Figure 19. Experimental results of dynamic performances with DCM load condition. (a) $v_{g s 1}, v_{g s 2}, v_{g s 3}$, $v_{g s, A u x 1}, v_{g s, A u x 2}, i_{L 1}, i_{L 2}$, transfer signal. (b) Change from the step-up mode to the step-down mode.

When the converter operates in $\mathrm{DCM}$ or $\mathrm{BCM}$, because the inductor current decreases to zero within one switching cycle, the energy conversion can be completed in one switching cycle. The controller combines analog and digital methods for the transfer state. On the other hand, when the converter operates in CCM, the path for the freewheeling of the inductor current must be provided to avoid the occurrence of voltage spikes on the power switches. Therefore, the inductor current of the converter in the CCM condition requires longer duration for reaching the steady state. The comparison of the transition times of the converter operating in different modes is shown in Table 3. 
Table 3. Comparisons of transition time.

\begin{tabular}{cccc}
\hline Mode & DCM & BCM & CCM \\
\hline Step-up to Step-down & $6.29 \mu \mathrm{s}$ & $7.04 \mu \mathrm{s}$ & $15.8 \mu \mathrm{s}$ \\
\hline Step-down to Step-up & $<20 \mu \mathrm{s}$ & $<20 \mu \mathrm{s}$ & $50.01 \mu \mathrm{s}$ \\
\hline
\end{tabular}

\subsection{Efficiency under Step-Up Mode}

The efficiency curve of the converter at step-up mode with different load conditions is illustrated in Figure 20. The result shows that the maximum efficiency is $96.37 \%$ at $40 \%$ load and the full load efficiency is $93.66 \%$.

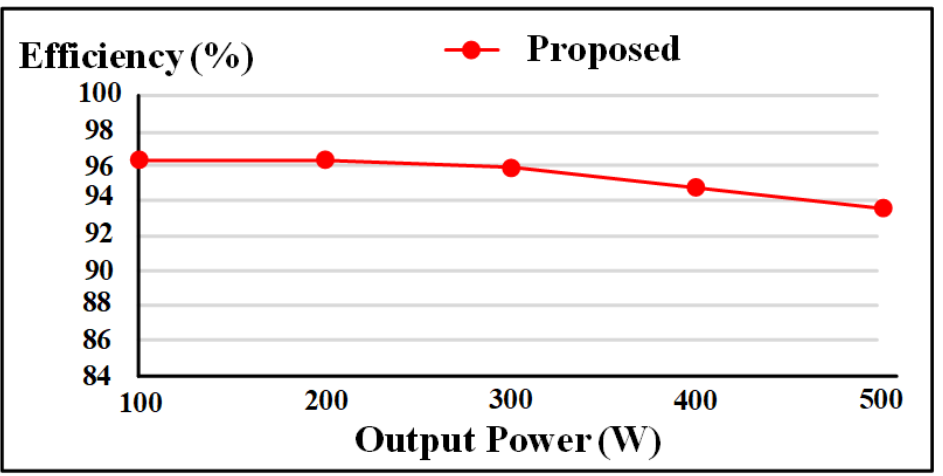

Figure 20. Efficiency curve under step-up mode.

\subsection{Efficiency under Step-Down Mode}

The efficiency curve of the converter at step-down mode for different load conditions is illustrated in Figure 21. The result shows that the maximum efficiency is $94.02 \%$ at $60 \%$ load and the full load efficiency is $93.08 \%$.

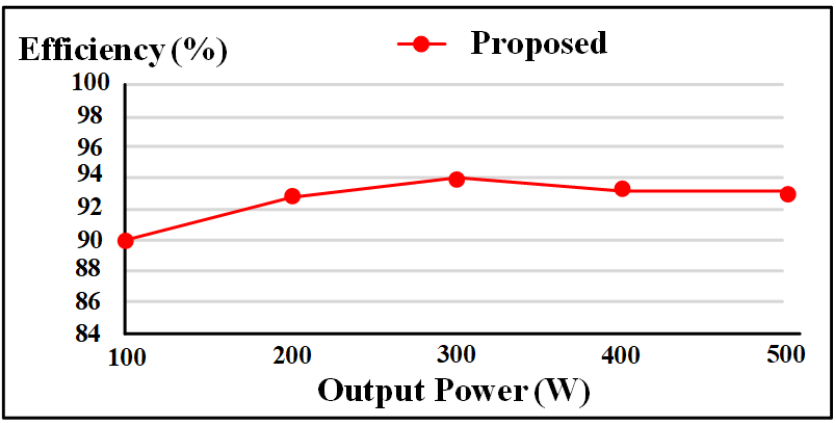

Figure 21. Efficiency curve under step-down mode.

\section{Conclusions}

The DC-DC converters have been widely used for connecting RES and ESS systems due to the need for energy storage for power generation with renewable energy. This paper proposes a bidirectional DC-DC converter with rapid energy conversion as the main circuit architecture for the energy conversion between the DC bus and the battery. The proposed method can improve the time required for energy transfer and provide smooth power flow under the same specification of the main components. In addition, the operational principles and the transferring states are analyzed in this paper.

A prototype converter for a $24 \mathrm{~V}$ battery, $200 \mathrm{~V}$ DC bus, and $500 \mathrm{~W}$ output power is constructed to confirm the feasibility of theoretical analyses. When the converter is operating in the step-up mode, the maximum efficiency of $96.37 \%$ is obtained at $40 \%$ load. In addition, the maximum efficiency of $94.02 \%$ is obtained at $60 \%$ load in the step-down 
mode. The experimental results presented indicated that the minimum transfer period is about $6.29 \mu$ s on the DCM stage. The resulting transition time for the experiment circuit can be completed within one switching cycle on DCM and BCM, and a minimum conversion time of $15.8 \mu$ s was obtained for the converter operating on CCM condition when stepup mode changed to step-down mode. Finally, the experimental results validate the effectiveness and precision of the proposed control strategies and rapid energy conversion.

While this study proposed a simplified idea for the feasibility of the theoretical proposal, many concerns can be discussed for future works. This includes constructing a complete system environment to control the converter, deriving a small-signal model of the converter, and improving the digital control design for a better conversion period.

Author Contributions: Conceptualization, J.-F.C. and B.-Z.C.; methodology, B.-Z.C.; validation, B.Z.C. and H.L.; original draft preparation, H.L.; writing-Review and editing, L.C.; supervision, J.-F.C. All authors have read and agreed to the published version of the manuscript.

Funding: This study is supported by the Delta Electronics Foundation, and it was financially supported by the Hierarchical Green-Energy Materials (Hi-GEM) Research Center, from The Featured Areas Research Center Program within the framework of the Higher Education Sprout Project by the Ministry of Education (MOE) in Taiwan, and the Ministry of Science and Technology under Project MOST 110-2221-E-006-125, MOST 110-2634-F-006-017.

Institutional Review Board Statement: Not applicable.

Informed Consent Statement: Not applicable.

Conflicts of Interest: The authors declare no conflict of interest.

\section{References}

1. Uang, Y.; Javanroodi, K.; Nik, V.M. Climate Change and Renewable Energy Generation in Europ-Long-Term Impact Assessment on Solar and Wind Energy High-Resilution Future Climate Data and Considering Climate Uncertainties. Energies 2022, 15, 302. [CrossRef]

2. Arraño-Vargas, F.; Shen, Z.; Jiang, S.; Fletcher, J.; Konstantinou, G. Challenges and measures in Power Systems with High Share of Renewables-The Australian Expperience. Energies 2022, 15, 429. [CrossRef]

3. Cardenas, B.; Styles, L.S.; Rouse, J.; Garvey, S.D. Short-, Medium- and Long-Duration Energy Storage in a $100 \%$ Reneable Electricity Grid: A UK Case Study. Energies 2022, 14, 8524. [CrossRef]

4. Chen, S.; Yang, B.; Pu, T.; Chang, C.; Lin, R. Active Current Sharing of a Parallel DC-DC Converters System Using Bat Algorithm Optimized Two-DOF PID Control. IEEE Access 2019, 7, 84757-84769. [CrossRef]

5. Bora, B.; Gudy, S.K. Performance and Analysis of Adaptable PI and SMC for a Hybrid PV-Battery System. In Proceedings of the 2020 IEEE International Women in Engineering (WIE) Conference on Electrical and Computer Engineering (WIECON-ECE), Bhubaneswar, India, 26-27 December 2020; pp. 84-89. [CrossRef]

6. Han, Y.; Ning, X.; Yang, P.; Xu, L. Review of Power Sharing, Voltage Restoration and Stabilization Techniques in Hierarchical Controlled DC Microgrids. IEEE Access 2019, 7, 149202-149223. [CrossRef]

7. Wu, H.; Sun, K.; Chen, L.; Zhu, L.; Xing, Y. High step-up/step-down soft-switching bidirectional DC-DC converter with coupled-inductor and voltage matching control for energy storage systems. IEEE Trans. Ind. Electron. 2016, 63, $2892-2903$. [CrossRef]

8. Kwon, O.; Kim, J.; Kwon, J.; Kwon, B. Bidirectional Grid-Connected Single-Power-Conversion Converter with Low-Input Battery Voltage. IEEE Trans. Ind. Electron. 2018, 65, 3136-3144. [CrossRef]

9. Liang, T.J.; Lee, J. Novel high-conversion-ratio high-efficiency isolated bidirectional DC-DC converter. IEEE Trans. Ind. Electron. 2015, 62, 4492-4503. [CrossRef]

10. Bai, S.; Lukic, S.M. Unified active filter and energy storage system for an MW electric vehicle charging station. IEEE Trans. Power Electron. 2013, 28, 5793-5803. [CrossRef]

11. Bryden, T.S.; Hilton, G.; Dimitrov, B.; de León, C.P.; Cruden, A. Rating a Stationary Energy Storage System Within a Fast Electric Vehicle Charging Station Considering User Waiting Times. IEEE Trans. Transp. Electrif. 2019, 5, 879-889. [CrossRef]

12. Venkatramanan, D.; John, V. A Reconfigurable Solar Photovoltaic Grid-Tied Inverter Architecture for Enhanced Energy Access in Backup Power Applications. IEEE Trans. Ind. Electron. 2020, 67, 10531-10541. [CrossRef]

13. IEEE Guide for Batteries for Uninterruptible Power Supply Systems (Revision of IEEE 1184-1994). In IEEE Std 1184-2006(R2011); IEEE: New York, NY, USA, 2006; pp. 1-73. [CrossRef]

14. Mozos, A.B.; Mouli, G.R.C.; Bauer, P. Evaluation of topologies for a solar powered bidirectional electric vehicle charger. IET Power Electron. 2019, 12, 3675-3687. [CrossRef] 
15. Zheng, Y.; Li, S.; Dey, S.; Smedley, K. Family of isolated bidirectional resonant converters with duty-cycle control and automatic power flow transition. IET Power Electron. 2018, 11, 1582-1590. [CrossRef]

16. Sharma, A.; Nag, S.S.; Bhuvaneswari, G.; Veerachary, M. An improved mode transition technique for a non-isolated bidirectional DC-DC converter. IEEE Trans. Circuits Syst. II 2020, 67, 3093-3097. [CrossRef]

17. Cornea, O.; Andreescu, G.; Muntean, N.; Hulea, D. Bidirectional power flow control in a DC microgrid through a switchedcapacitor cell hybrid DC-DC converter. IEEE Trans. Ind. Electron. 2017, 64, 3012-3022. [CrossRef]

18. Vuyyuru, U.; Maiti, S.; Chakraborty, C. Active power flow control between DC Microgrids. IEEE Trans. Smart Grid 2019, 10, 5712-5723. [CrossRef]

19. Bayati, M.; Farahmandrad, M.; Tehrani, K. More and Faster Energy Transfer Capability for Battery Chargers of Electric Vehicles. In Proceedings of the 2021 World Automation Congress (WAC), Paris, France, 24-26 August 2021; pp. 228-232. [CrossRef]

20. Khan, I.A.; Pi, D.; Yue, P.; Li, B.; Khan, Z.U.; Hussain, Y.; Nawaz, A. Efficient behavior specification and bidirectional gated recurrent units-based intrusion detection method for industrial control systems. IET Electron. Lett. 2020, 56, 27-30. [CrossRef]

21. Callegaro, L.; Ciobotaru, M.; Pagano, D.J.; Turano, E.; Fletcher, J.E. A simple smooth transition technique for the noninverting buck-boost converter. IEEE Trans. Power Electron. 2018, 33, 4906-4915. [CrossRef]

22. Tang, Y.; Chen, Y.; Madawala, U.K.; Thrimawithana, D.J.; Ma, H. A new controller for bidirectional wireless power transfer systems. IEEE Trans. Power Electron. 2018, 33, 9076-9087. [CrossRef]

23. $\mathrm{Xu}, \mathrm{J}$. PWM modulation and control strategy for LLC-DCX converter to achieve bidirectional power flow in facing with resonant parameters variation. IEEE Access 2019, 7, 54693-54704. [CrossRef]

24. Waghmare, T.; Chaturvedi, P. Study of Bidirectional DC-DC Converter: Control Schemes and Switching Techniques. In Proceedings of the 2020 IEEE First International Conference on Smart Technologies for Power, Energy and Control (STPEC), Nagpur, India, 25-26 September 2020; pp. 1-6. [CrossRef]

25. Bhaskar, M.S.; Meraj, M.; Iqbal, A.; Padmanaban, S. Nonisolated Symmetrical Interleaved Multilevel Boost Converter with Reduction in Voltage Rating of Capacitors for High-Voltage Microgrid Applications. IEEE Trans. Ind. Appl. 2019, 55, 7410-7424. [CrossRef]

26. Zhu, R.; Hoffmann, F.; Vázquez, N.; Wang, K.; Liserre, M. Asymmetrical bidirectional DC-DC converter with limited reverse power rating in smart transformer. IEEE Trans. Power Electron. 2020, 35, 6895-6905. [CrossRef] 